\title{
C-reactive protein: what to expect after bony hip surgery for non- ambulatory children and adolescents with cerebral palsy
}

\section{Running head}

CRP after bony hip surgery in children with CP

\author{
Authors \\ Alastair G DICK a - Orthopaedic Specialty Registrar \\ Nicholas MAGILL ${ }^{b}$ - Research Student \\ Thomas C H WHITE a- Locum Consultant Orthopaedic Surgeon \\ Michail KOKKINAKIS a- Consultant Orthopaedic Surgeon \\ Fabian NORMAN-TAYLOR a- Consultant Orthopaedic Surgeon
}

\begin{abstract}
Affiliations
a - Evelina London Children's Hospital, Westminster Bridge Road, London, SE1 7EH, UK

b - Institute of Psychiatry, Psychology and Neuroscience. 16 De Crespigny Park, SE5 8AF, UK
\end{abstract}

\section{Corresponding Author}

Alastair G Dick

Department of Orthopaedics

Evelina London Children's Hospital

Guy's \& St Thomas' NHS Foundation Trust

Westminster Bridge Road

London

SE1 7EH

alastair.dick@nhs.net

Conflicts of interest and sources of funding

None declared 


\section{Abstract}

2

3 Objectives

4 Bony hip reconstruction surgery in children with severe cerebral palsy (CP) is

5 associated with high complication rates, usually post-operative chest and urinary

6 tract infections. C-reactive protein (CRP) level is commonly used as an indication of

7 infection; an understanding of its normal post-operative trends is crucial to allow

8 early identification of abnormal levels and possible infection. Our aim was to

9 describe the trends in CRP following bony hip surgery in children who had an uneventful post-operative course, on the basis that the children for whom CRP does not follow this course are likely to have a bacterial infection.

\section{Methods}

A retrospective review was performed of 155 children with $\mathrm{CP}$ having bony hip surgery between 2012 and 2016. The median age was 9.9 years (interquartile range 6.6-12.7). One hundred (64.5\%) patients had a Gross Motor Function Classification System rating of $\mathrm{V}$. All CRP levels measured in routine post-operative care were recorded, and medical records were examined for post-operative infective complications. The CRP levels of patients with clinically proven infections were excluded in order to describe what to expect in the absence of infection.

\section{Results}

Mean CRP peaked on the third post-operative day at $81 \mathrm{mg} / \mathrm{L}$ in those who had no post-operative infection. Twenty-five patients (16.1\%) had a post-operative infection; their mean CRP was higher on all post-operative days and peaked at $128 \mathrm{mg} / \mathrm{L}$ on the third post-operative day.

\section{Conclusions}

An understanding of the normal post-operative trends in CRP allows identification of those with abnormally raised levels. Post-operative CRP is consistently higher in children with an infective complication. We recommend that the CRP should be routinely checked following bony hip surgery in children with $\mathrm{CP}$, and a careful search for infection undertaken in those with a raised level. 
35

36 Keywords

37

38 Hip Dislocation

39 Cerebral Palsy

40 C-reactive Protein

41 Postoperative Complications

42

43 


\section{Introduction}

Subluxation and dislocation of the hip has been reported in up to $60 \%$ of nonambulatory children with cerebral palsy (CP) [1]. Severe subluxation or dislocation can cause pain, seating problems and issues with perineal hygiene [2,3]. Surgery is indicated in cases of severe or progressive subluxation and aims to maintain reduced, pain free hips using a combination of soft tissue releases, proximal femoral and pelvic osteotomies [2] . Hip reconstruction surgery has been shown to result in a lasting reduction in pain intensity and frequency in children with CP [4]. A recent systematic review is supportive of the usage of combined pelvic and femoral reconstruction over isolated femoral osteotomy [5]. Surgery, especially combined pelvi-femoral hip reconstruction, can be extensive and has been reported to have complication rates as high as $81 \%$ [6]. Complications are more common following surgery in those with more severe disease as classified by the Gross Motor Function Classification System (GMFCS) [7]. Medical complications including post-operative urinary tract infection and respiratory complications are more common in CP than non CP children undergoing hip osteotomies [8]. Many children with severe CP are unable to communicate the symptoms associated with post-operative infection and thus diagnosis and treatment may be delayed. It is NHS England policy to promote the early detection of infection in order to prevent sepsis [9]; and there is current National Institute for Health and Care Excellence (NICE) guidance on the early identification of infections, including the measurement of C-reactive protein (CRP) in children [10], although no diagnostic CRP level has been proposed. C-reactive protein (CRP) is an acute phase serum protein synthesised in the liver that rises rapidly in response to inflammation [11]. CRP is commonly used as an indicator of infection and response to treatment. Póvoa et al found a CRP of greater than $50 \mathrm{mg} / \mathrm{L}$ to be highly suggestive of sepsis [12]. Interpretation of CRP as a marker of infection in the post-operative period can be challenging as the inflammation of surgical trauma itself will increase the CRP [13,14]. An understanding of the usual CRP response to surgery is crucial to allow the clinical team to identify the abnormally increased response that may occur with postoperative infection. 
78 The post-operative kinetics of CRP have been described in the paediatric population in a relatively small cohort across a broad range of pan-specialty procedures [15] and in a small number of children undergoing a range of orthopaedic procedures [16]. We could find no description in the literature of the trends of CRP following bony hip surgery in children with severe $\mathrm{CP}$.

The aim of our study was to identify the trends of CRP following bony hip surgery in children and adolescents with CP. We aimed to describe the expected trend in post-operative CRP levels so that those individuals with a post-operative infection can be detected more easily.

\section{Methods}

We performed a retrospective review of all children with CP undergoing bony hip surgery for hip subluxation/dislocation at our tertiary referral children's hospital between April 2012 and December 2016. All children received intravenous antibiotic prophylaxis at induction with cefuroxime or teicoplanin if allergic to penicillin. We recorded all CRP levels that had been measured as part of routine care in the first five post-operative days. We examined the medical records for evidence of postoperative infective complications. Post-operative infection was defined on the clinical assessment of a paediatrician in combination with appropriate microbiological or radiological findings. Patients were placed in one of two groups defined by the presence or absence of a post-operative infective complication.

Statistical analyses were undertaken using SPSS (Version 24.0, IBM Corporation, Armonk, NY, USA). The mean CRP and standard deviation for each post-operative day were calculated. Chi squared test was used to assess statistical significance for categorical data.

Ethical approval was not required as the study was retrospective and all data analysed were already collected in the course of normal clinical care. 
114 One hundred and fifty-five patients' records were included in the study with a median age of 9.9 (inter-quartile range 6.6-12.7). There were 103 males (66.5\%) and 52 females (33.5\%). Demographics of the cohort are in Table 1. Procedures performed were 14 unilateral derotation varus osteotomies (DVRO) (9.0\%), 47 bilateral DVROs (30.3\%), 36 unilateral pelvi-femoral reconstructions (23.2\%), 26 bilateral pelvifemoral reconstructions (16.8\%), 18 revision hip reconstructions (11.6\%), 13 proximal femoral resections $(8.4 \%)$ and one shelf procedure $(0.6 \%)$. There were 25 cases complicated by post-operative infection (16.1\%). Of these infections, there were 18 lower respiratory tract infections (LRTI), 2 urinary tract infections (UTI), 3 combined LRTI and UTI, 1 gastrointestinal infection and 1 surgical site infection. The demographics of those with a post-operative complication are presented in Table 2. There was no significant difference in post-operative infection rate between those undergoing unilateral procedures $(13 / 77,16.9 \%)$ and bilateral procedures $(12 / 78,15.4 \%)(p=0.80)$. All patients with a post-operative infection had a GMFCS of $\mathrm{V}$. One patient had a pre-operative CRP of $45 \mathrm{mg} / \mathrm{L}$, all others had a pre-operative CRP of less than $8 \mathrm{mg} / \mathrm{L}$. Mean post-operative CRP was higher on every postoperative day in those with an infective complication. CRP peaked on the third postoperative day at $81 \mathrm{mg} / \mathrm{L}$ in those without an infective complication and $128 \mathrm{mg} / \mathrm{L}$ in those with an infective complication before trending towards normal. The trends in post-operative CRP level are presented in Table 3 and Figure 1 and 2.

\section{Discussion}

This study describes the normal CRP changes seen after bony hip surgery in CP patients. It demonstrates that the CRP peaks on the third post-operative day then declines towards baseline. This pattern is similar to that reported in the adult literature including patients undergoing total hip arthroplasty [17-20]. Limpisvasti et al described the trends of post-operative CRP in 22 children undergoing a range of elective orthopaedic procedures (without post-operative infective complication) finding a peak on day 3 averaging $73 \mathrm{mg} / \mathrm{L}$ [16]. We report slightly higher absolute levels of CRP than their study, and this may reflect the extensive nature of CP bony hip surgery. We also note a broad range of CRP between patients. This may in part 
146 relate to whether or not the child had bilateral procedures, and whether or not an

147 acetabuloplasty was performed; there were not enough patients included to

148 ascertain whether there are statistically significant differences between these

149 procedures.

150 We report an increased CRP level in those with post-operative infections on all of the

151 first five post-operative days. Baez et al described the post-operative kinetics of

152 CRP in 103 paediatric patients undergoing a broad range of pan-speciality surgical

153 procedures and found a rise of $110 \mathrm{mg} / \mathrm{L}$ in 48 hours to be predictive of infection [15].

154 We report an overall rate of post-operative infective complications of $16.1 \%$; this is

155 similar to that reported in the recent large series of CP hip reconstructions by Rutz

156 and colleagues of $15.7 \%$ [4]

\section{Limitations}

The study did not include the participants' pre-operative medical co-morbidities, and although the GMFCS level gives a reasonable indication of what they were likely to be, we cannot comment on how they may have affected the trends in post-operative CRP. The study was retrospective and relied on blood tests taken as part of routine care. CRP was measured routinely pre- and post-operatively, but the number of patients having the test reduced with each post-operative day. A higher proportion of patients in the infection group had their CRP checked throughout their admission, and this could result in bias.

\section{Conclusion}

175 An understanding of the normal post-operative trends in CRP allows identification of

176 those with abnormally raised levels. Post-operative CRP is consistently higher in

177 patients with an infective complication. These data support the routine post-

178 operative monitoring of CRP in this patient group. We recommend that the CRP 179 should be routinely checked following bony hip surgery in non-ambulant paediatric 
180 patients with $\mathrm{CP}$, and a careful search for infection undertaken in those with a raised

181 level, with the early involvement of paediatric colleagues and consideration of

182 antibiotic therapy.

183

184 


\begin{tabular}{|c|c|c|}
\hline \multicolumn{3}{|l|}{ Demographics } \\
\hline \multirow{2}{*}{$\begin{array}{c}\text { Age in years }(n=155) \\
-\quad \text { Median }[\mathrm{IQR}]\end{array}$} & & \\
\hline & 9.9 & {$[6.6-12.7]$} \\
\hline & $\mathbf{n}$ & $(\%)$ \\
\hline \multicolumn{3}{|l|}{ Age group $(n=155)$} \\
\hline$-0-5$ & 22 & $(14.2)$ \\
\hline$-\quad 5-10$ & 57 & $(36.8)$ \\
\hline$-\quad 10-15$ & 53 & (34.2) \\
\hline$-\quad 15-20$ & 23 & $(14.8)$ \\
\hline \multicolumn{3}{|l|}{ Gender $(n=155)$} \\
\hline - Male & 103 & $(66.5)$ \\
\hline Female & 52 & (33.5) \\
\hline \multicolumn{3}{|l|}{ GMFCS $(n=155)$} \\
\hline-1 & 0 & $(0.0)$ \\
\hline$-\quad I I$ & 2 & $(1.3)$ \\
\hline$-\quad$ III & 3 & $(1.9)$ \\
\hline$-\quad$ IV & 50 & (32.3) \\
\hline$-\quad V$ & 100 & $(64.5)$ \\
\hline Procedure $(n=155)$ & n & $(\%)$ \\
\hline - Unilateral DVRO & 14 & $(9.0)$ \\
\hline - $\quad$ Bilateral DVRO & 47 & (30.3) \\
\hline - Unilateral hip reconstruction & 36 & (23.2) \\
\hline - Bilateral hip reconstruction & 26 & $(16.8)$ \\
\hline - Revision hip reconstruction(s) & 18 & $(11.6)$ \\
\hline - $\quad$ Proximal femoral resection(s) & 13 & $(8.4)$ \\
\hline - $\quad$ Shelf & 1 & $(0.6)$ \\
\hline Unilateral or bilateral $(n=155)$ & $\mathbf{n}$ & (\%) \\
\hline - Unilateral & 77 & $(49.7)$ \\
\hline - Bilateral & 78 & $(50.3)$ \\
\hline \multicolumn{3}{|c|}{ Post operative infective status $(n=155)$} \\
\hline No post-operative infection & 130 & (83.9) \\
\hline Post-operative infection & 25 & $(16.1)$ \\
\hline - LRTI & 18 & $(11.6)$ \\
\hline - UTI & 2 & $(1.3)$ \\
\hline - $\quad$ LRTI + UTI & 3 & $(1.9)$ \\
\hline - Gastrointestinal infection & 1 & $(0.6)$ \\
\hline - Surgical site infection & 1 & $(0.6)$ \\
\hline
\end{tabular}
Classification System; DVRO, derotation varus osteotomy; LRTI, lower respiratory tract infection; UTI, urinary tract infection. 


\begin{tabular}{|l|c|l|}
\hline Operation & Age & \multicolumn{1}{|c|}{ Infection } \\
\hline Bilateral DVRO, bilateral acetabuloplasty & 4.2 & LRTI \\
\hline Bilateral DVRO & 3.5 & UTI, LRTI \\
\hline Left open reduction, DVRO, acetabuloplasty & 4.7 & LRTI \\
\hline Left revision DVRO, triple osteotomy & 11.1 & LRTI \\
\hline Bilateral DVRO, left acetabuloplasty & 5.3 & LRTI \\
\hline Bilateral DVRO & 9.3 & LRTI, UTI \\
\hline Bilateral DVRO, left acetabuloplasty & 11.5 & LRTI \\
\hline Right open reduction, DVRO, acetabuloplasty & 6.9 & LRTI \\
\hline Bilateral DVRO & 9.9 & LRTI, UTI \\
\hline Bilateral DVRO, left acetabuloplasty & 10.1 & LRTI \\
\hline Left DVRO, acetabuloplasty & 15.1 & LRTI \\
\hline Bilateral DVRO, left acetabuloplasty & 4.5 & LRTI \\
\hline Bilateral DVRO & 6.6 & LRTI \\
\hline Left DVRO, acetabuloplasty & 12.1 & Surgical site \\
\hline Bilateral DVRO & 4.8 & Enterocolitis \\
\hline Right DVRO, acetabuloplasty & 13.3 & LRTI \\
\hline Left open reduction, DVRO, acetabuloplasty & 6.8 & UTI \\
\hline Bilateral DVRO & 5.4 & LRTI \\
\hline Left revision open reduction, DVRO, acetabuloplasty & 10.9 & LRTI \\
\hline Right open reduction, DVRO, acetabuloplasty & 11.1 & LRTI \\
\hline Bilateral DVRO, right acetabuloplasty & 9.3 & LRTI \\
\hline Right revision DVRO & 7.2 & LRTI \\
\hline Right DVRO, right pelvic osteotomy & 18.7 & UTI \\
\hline Left revision DVRO, acetabuloplasty & 12.5 & LRTI \\
\hline Right proximal femoral resection & 12.4 & LRTI \\
\hline
\end{tabular}

Table 2 - Demographics of child -operative comren with postplications (all had a GMFCS of V)

Abbreviations - GMFCS, Gross Motor Function Classification System; DVRO, 


\begin{tabular}{|c|c|c|c|c|}
\hline & \multicolumn{2}{|c|}{$\begin{array}{l}\text { No infective complication } \\
\qquad(\mathrm{n}=130)\end{array}$} & \multicolumn{2}{|c|}{ Infective complication $(\mathrm{n}=25)$} \\
\hline & $\begin{array}{c}\text { CRP checked } \\
(\%)\end{array}$ & $\begin{array}{c}\text { CRP }(\mathrm{mg} / \mathrm{L}) \\
\text { Mean (SD) }\end{array}$ & $\begin{array}{c}\text { CRP checked } \\
(\%)\end{array}$ & $\begin{array}{l}\text { CRP }(\mathrm{mg} / \mathrm{L}) \\
\text { Mean }(\mathrm{SD})\end{array}$ \\
\hline Day 1 & $106(81.5)$ & $31.4(29.3)$ & $24(96.0)$ & $44.9(28.4)$ \\
\hline Day 2 & $68(52.3)$ & $79.3(56.6)$ & $21(84.0)$ & $107.5(65.0)$ \\
\hline Day 3 & $40(30.8)$ & $81.0(62.1)$ & $18(72.0)$ & $128.1(91.2)$ \\
\hline Day 4 & 24 (18.5) & $74.7(60.2)$ & $15(60.0)$ & $112.2(79.4)$ \\
\hline Day 5 & $6(4.6)$ & $57.0(36.4)$ & $14(56.0)$ & $102.2(77.0)$ \\
\hline
\end{tabular}

219 Table 3 - Post-operative mean CRP and standard deviation for each post-operative 220 day. CRP checked refers to the proportion of children who had a CRP level

221 performed on that post-operative day. 


\section{Figure legends}

225

226

227 Figure 1 - Post-operative trend in CRP in those patients with no post-operative 228 infective complication. Data are shown as mean $+/$ - standard error of the mean. 229 230

231

232 Figure 2 - Post-operative trends in CRP comparing those patients with a post-

233 operative infective complication and those without. Data are shown as mean +/234 standard error of the mean. 
2381 Valencia FG. Management of Hip deformities in cerebral palsy. Orthop Clin North Am 2010;41:549-59. doi:10.1016/j.ocl.2010.07.002 palsy. Orthop Clin North Am 2006;37:185-96, vi. doi:10.1016/j.ocl.2005.11.001 Flynn JM, Miller F. Management of hip disorders in patients with cerebral palsy. J Am Acad Orthop Surg 2002;10:198-209.

$244 \quad$ Rutz E, Vavken P, Camathias C, et al. Long-term results and outcome predictors in one-stage hip reconstruction in children with cerebral palsy. $J$ Bone Joint Surg Am 2015;97:500-6. doi:10.2106/JBJS.N.00676 palsy children Gross Motor Function Classification System levels III to V: A systematic review. J Pediatr Orthop Part B 2018;27:221-30. doi:10.1097/BPB.0000000000000503

Ruzbarsky JJ, Beck NA, Baldwin KD, et al. Risk factors and complications in hip reconstruction for nonambulatory patients with cerebral palsy. J Child Orthop 2013;7:487-500. doi:10.1007/s11832-013-0536-1

Stasikelis PJ, Lee DD, Sullivan CM. Complications of osteotomies in severe cerebral palsy. J Pediatr Orthop 1999;19:207-10.

DiFazio R, Vessey JA, Miller P, et al. Postoperative Complications After Hip Surgery in Patients With Cerebral Palsy: A Retrospective Matched Cohort Study. J Pediatr Orthop 2015;36:56-62. doi:10.1097/BPO.0000000000000404 England NHS. Improving outcomes for patients with sepsis A cross-system action plan. NHS Engl Published Online First: 2015.https://www.england.nhs.uk/wp-content/uploads/2015/08/Sepsis-ActionPlan-23.12.15-v1.pdf

10 Excellence $\mathrm{NI}$ for $\mathrm{H}$ and $\mathrm{C}$. Sepsis: recognition, diagnosis and early management. London, UK: 2016. https://www.nice.org.uk/guidance/ng51

11 Marnell L, Mold C, Du Clos TW. C-reactive protein: ligands, receptors and role in inflammation. Clin Immunol 2005;117:104-11. doi:10.1016/j.clim.2005.08.004

12 Povoa $\mathrm{P}$, Almeida E, Moreira $\mathrm{P}$, et al. C-reactive protein as an indicator of sepsis. Intensive Care Med 1998;24:1052-6. 
13 Cole DS, Watts A, Scott-Coombes D, et al. Clinical utility of peri-operative Creactive protein testing in general surgery. Ann $R$ Coll Surg Engl 2008;90:31721. doi:10.1308/003588408X285865

14 Mok JM, Pekmezci M, Piper SL, et al. Use of C-reactive protein after spinal surgery: comparison with erythrocyte sedimentation rate as predictor of early postoperative infectious complications. Spine (Phila Pa 1976) 2008;33:415-21. doi:10.1016/S0276-1092(08)79414-8

15 Baez YL, Rodriguez MAP, De Vicente Sánchez JC, et al. C-reactive protein in the diagnosis of postoperative infection in pediatric patients: A prospective observational study of 103 patients. J Pediatr Surg 2011;46:1726-31. doi:10.1016/j.jpedsurg.2011.03.014

16 Limpisvasti O, Yandow SM, Raney EM. C-reactive protein response following pediatric orthopaedic surgery. J Pediatr Orthop 2004;24:574-5.

17 Larsson S, Thelander U, Friberg S. C-reactive protein (CRP) levels after elective orthopedic surgery. Clin Orthop Relat Res 1992;:237-42.

18 Niskanen RO, Korkala O, Pammo H. Serum C-reactive protein levels after total hip and knee arthroplasty. J Bone Joint Surg Br 1996;78:4313.http://eutils.ncbi.nlm.nih.gov/entrez/eutils/elink.fcgi?dbfrom=pubmed\&id=863 6181\&retmode=ref\&cmd=prlinks\%5Cnpapers2://publication/uuid/038DD9136B1A-4CFD-B5FC-E94631F2B013

19 White J, Kelly M, Dunsmuir R. C-reactive protein level after total hip and total knee replacement. J Bone Joint Surg Br 1998;80:909-11.

20 Shen $\mathrm{H}$, Zhang $\mathrm{N}$, Zhang $\mathrm{X}$, et al. C-reactive protein levels after 4 types of arthroplasty. Acta Orthop 2009;80:330-3. doi:10.3109/17453670903066596 
Figure 1

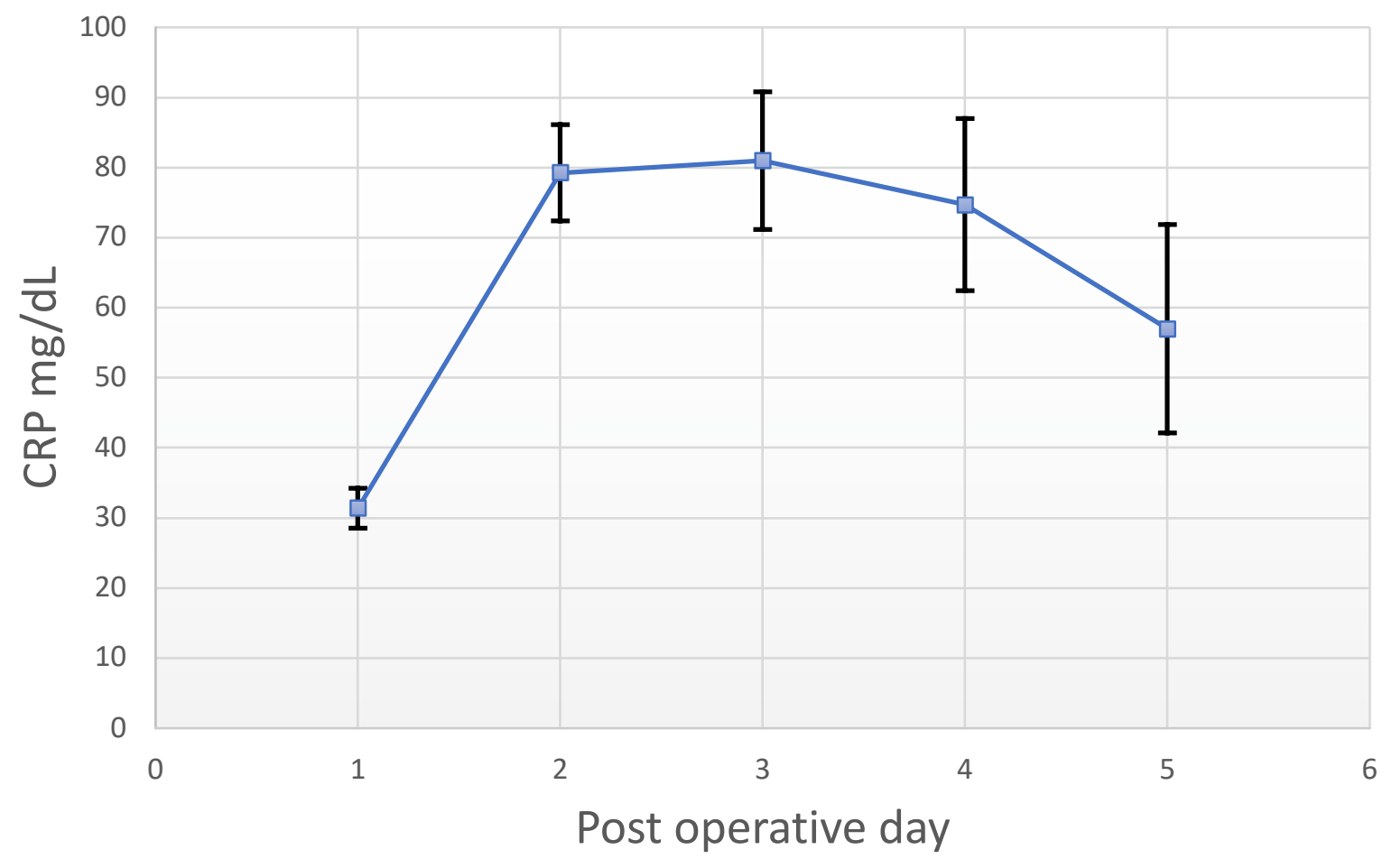


Figure 2

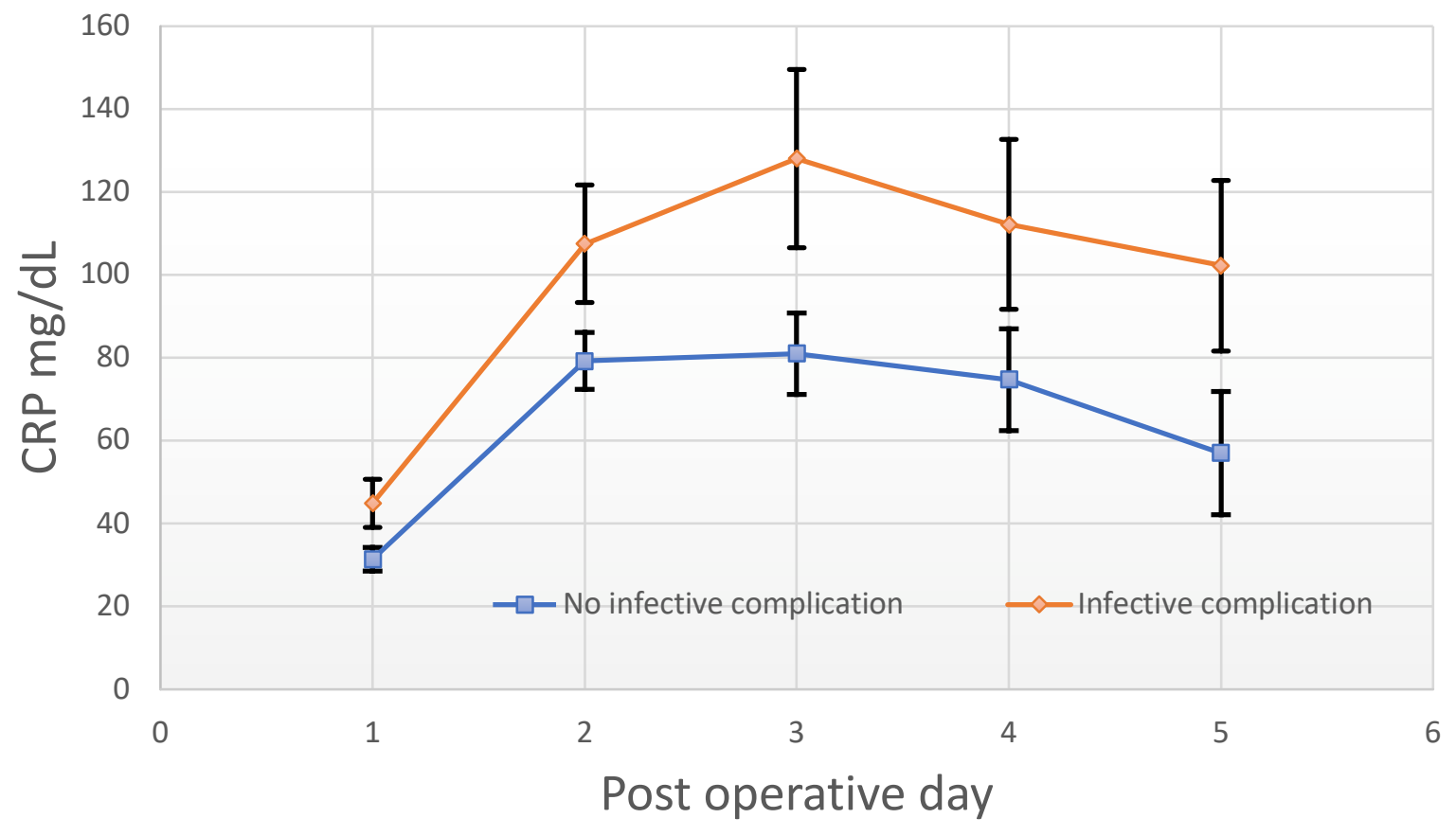

